\title{
Effect on doctors' work load of a campaign to encourage early reporting of breast symptoms
}

\author{
SALLY NICHOLS AND W E WATERS \\ From Community Medicine, University of Southampton, Southampton SO9 $4 X Y$, UK
}

SUMMARY A public health education campaign to encourage early reporting of breast symptoms was held in Southampton during February 1981. General practitioners kept a record of women Consulting them about breast symptoms. The results were confounded by a recording behaviour effect but provided no evidence of a pronounced increase in their work load. There was no overall increase in hospital outpatient work load.

Concern is often expressed that a health education campaign advising the public to report breast symptoms to their general practitioner without delay will result in a sudden flood of patients, thereby putting the primary care services under increased pressure. Furthermore, this might subsequently cause an increase in work load in hospital clinics. There do not appear, however, to have been any evaluative studies in Britain to test such a view, although one in Australia gave inconclusive results. ${ }^{1}$

\section{Method}

A public health education campaign to encourage the early reporting of breast symptoms was held in Southampton throughout February $1981 .^{2}$ In January letters about the campaign were sent to all 120 NHS general practitioners, including trainees, practising in the city. Those who had recorded numbers of women consulting them about breast symptoms for four weeks in $1980^{3}$ were asked to record again, for eight weeks, during February and March 1981. The remainder (28), who had been unable to record previously or were new to Southampton, were asked to help; 23 who agreed were subsequently seen to explain the study and method of recording. The recording booklets, identical to those used in 1980 (control period), provided information about the number of consultations (new episodes and follow-ups), the age and presenting symptom(s) of each woman, and the action taken by the general practitioner.

In the control period general practitioners recorded consultations about breast symptoms for four consecutive weeks sometime between January and March 1980, immediately after an interview with
SN on the management of female breast disease. ${ }^{3}$ Thus the number of general practitioners varied daily as some began and others finished recording. The maximum number recording on one day (64) was reached in mid-February. In contrast, during February and March 1981 all doctors recorded throughout the same eight weeks (study period).

The number of new patients resident within the Southampton city boundaries and attending the breast clinic and the interval between their referral by a doctor and outpatient attendance (hospital delay) were being routinely collected. ${ }^{4}$

\section{Results}

\section{GENERAL PRACTITIONER WORK LOAD}

Altogether 102 Southampton general practitoners $(85 \%)$ completed a record of women consulting them about breast symptoms during the study period. More new episodes and follow-ups were recorded in the 1980 control period than during the month of the public campaign (February 1981) or the following month, although fewer general practitioners took part (93) (table 1).

Table 1 Number of consultations about breast symptoms recorded by Southampton general practitioners during the 1980 control period and the study period of February (the month of the public campaign) and March 1981

\begin{tabular}{lllll}
\hline & 1980 & & 1981 & \\
\cline { 2 - 4 } \cline { 5 - 6 } Consultations & Control month & & February & March \\
\hline New episodes & 241 & & 215 & 123 \\
Follow-ups & 90 & 63 & 52 \\
Total consultations & 331 & 278 & 175
\end{tabular}


For comparison with the study period, the control data were analysed over calendar time and by week of recording. The mean number of new episodes per general practitioner declined over the study period, except for three weeks during February (the month of the public campaign) when the number remained relatively constant. During the same months of the control period the mean number fluctuated but showed a less steady fall. In the control period there were more new episodes per general practitioner in the first recording week and there was a sharper decline in mean numbers over recording weeks than in the study period.

The ages and presenting symptoms of the new episodes were similar during the control and study periods. There was a high degree of consistency in the action taken by the general practitioners during the two periods (table 2).

\section{HOSPITAL OUTPATIENT WORKLOAD}

The median duration of hospital delay was greater during the months of the 1981 study period than

Table 2 Number and percentage of patients with new episodes of breast symptoms according to the action taken by Southampton general practitioners during the 1980 control period and the study period of February (the month of the public campaign) and March 1981

\begin{tabular}{|c|c|c|c|c|c|c|}
\hline \multirow[b]{3}{*}{$\begin{array}{l}\text { Action taken by } \\
\text { general practitioners }\end{array}$} & \multirow{2}{*}{\multicolumn{2}{|c|}{$\frac{1980}{\text { Control month }}$}} & \multicolumn{4}{|l|}{1981} \\
\hline & & & \multicolumn{2}{|c|}{ February } & \multicolumn{2}{|l|}{ March } \\
\hline & $\begin{array}{l}\text { No of } \\
\text { patients }\end{array}$ & (\%) & $\begin{array}{l}\text { No of } \\
\text { patients }\end{array}$ & (\%) & $\begin{array}{l}\text { No of } \\
\text { patients }\end{array}$ & (\%) \\
\hline Referred to hospital & 61 & 25 & 54 & 25 & 29 & 24 \\
\hline To return to GP & 83 & 34 & 70 & 33 & 37 & 30 \\
\hline Reassured only & 97 & 40 & 90 & 42 & 55 & 45 \\
\hline Unknown & $\mathbf{0}$ & - & 1 & - & 2 & 1 \\
\hline All new episodes & 241 & 100 & 215 & 100 & 123 & 100 \\
\hline
\end{tabular}

during the corresponding period of 1979 (a "no interventions" year) (fig). The decrease in the median duration of delay between January and March was steeper in 1981 than 1979. The figure also shows a peak in new attendances at the breast clinic in February 1981 followed by a trough during April and May. By June the number was similar to 1979 . In contrast, overall there was a steady increase in numbers over the first six months of 1979.

\section{Discussion}

\section{GENERAL PRACTITIONER WORKLOAD}

The decline in the mean number of new episodes per general practitioner during the study period is unlikely to be due to a seasonal effect, since during the control period a similar steady fall was not found. This is supported by the figure, which shows that in 1979 the number of new attendances at the breast clinic increased during these months. The analysis by week of recording suggests that the decline may be due to an understandable fall-off in efficiency of recording by the general practitoners. Hill ${ }^{1}$ interpreted some of his results in the same way. Nevertheless, the mean number of new episodes did remain almost constant during the latter three weeks of the public campaign. This could reflect either increased motivation by the general practitoners because of their awareness of the campaign, or a small increase in the number of women presenting with breast symptoms as a result of the campaign. The greater mean number of new episodes recorded during the first recording week of the control period may be the result of each general practitioner starting to record the day after an interview about breast disease. This was likely to have increased their awareness of breast problems, perhaps resulting in a

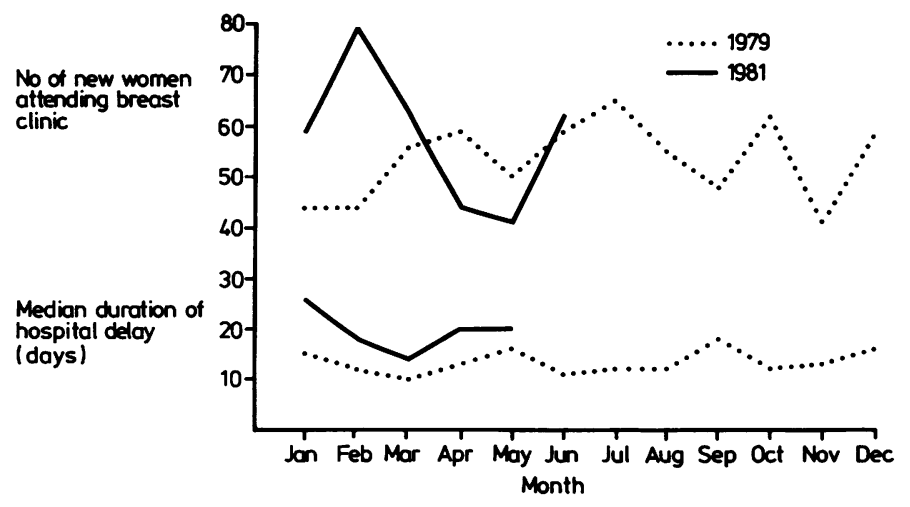

Median duration of hospital delay and number of new women outpatients during 1979 and 1981 (the year of the public health education campaign). 
higher proportion of patients being recorded. Comments from general practitoners support this explanation.

\section{HOSPITAL OUTPATIENT WORK LOAD}

In Southampton $79 \%$ of all breast operations are done by staff of the breast clinic (operations index 1978). While women living outside the city boundaries are referred to the breast clinic in Southampton because of its specialisation and high reputation, it seems unlikely that Southampton women are referred elsewhere in the region. Thus Southampton women attending the breast clinic should be representative of all Southampton women with breast disease. Although the departure of the surgeon in charge of the breast clinic in December 1980 could have influenced general-practitioner referral patterns after that date, this is unlikely since all local general practitioners were informed by the surgeon that the breast clinic would continue under the expertise offered by other members of staff.

The sharp increase, during February 1981, in the number of new Southampton patients attending the breast clinic cannot be accounted for by an effect of the public campaign on general practitioners and the public. Any such increase in hospital work load could not have occurred so soon. This apparently instantaneous effect of the campaign is probably due to the hospital staffs' awareness of the campaign; this may have caused them, during January 1981, to increase the number of appointments to clear any backlog in anticipation of a "rush" after the campaign. This interpretation is supported by two findings. Firstly, the peak in attendances in February was followed by a trough that would not have occurred if there had been any "real" increase in numbers. Secondly, there was a corresponding decrease in the median duration of hospital delay for patients attending the breast clinic in February. A reduced waiting time for these patients would be an inevitable consequence of quick appointments for January referrals.

\section{Conclusions}

This study of the effect of a public campaign on general practitioner and hospital outpatient work loads has highlighted the difficulties often involved in the interpretation of data. This was particularly the case for the general practitioner data where the results were confounded by a recording behaviour effect. The main objective of the campaign was to reduce patient delay. Whether or not this had been achieved will be assessed after 12 months. The records kept by general practitioners provide no evidence of any pronounced increase in breast symptom presentation; only detailed examination of the figures suggested an increase. Similarly, outpatient attendances at the breast clinic and their duration of hospital delay show that the public campaign in February 1981 did not lead to any overall increase in hospital outpatient work load. It suggests however, that hospital staff reacted in advance of the campaign, thereby creating a "busy" time before and during the campaign that was followed by a slacker period.

This study was supported by a grant from the Department of Health and Social Security through the Wessex Regional Cancer Organisation. We thank Southampton general practitioners for their continued co-operation, Martin Harman for computing help, and Joyce Riley for typing.

\section{References}

${ }^{1}$ Hill DJ. Evaluation of publicity and self-detection procedures for breast cancer. In: Maltoni C, ed. Advances in tumour prevention, detection and characterization. Vol 2. Cancer detection and prevention. Amsterdam: Excerpta Medica; 1974: 566-9.

${ }^{2}$ Christmas P, Nichols S. "Don't take a chance"-a public campaign to encourage the early reporting of breast symptoms. Health Educ $J$ (in press).

${ }^{3}$ Nichols S, Waters WE, Wheeller MJ. Management of female breast disease by Southampton general practitoners. Br Med J 1980; 281: 1450-3.

4 Nichols S, Waters WE, Fraser JD, Wheeller MJ, Ingham SK. Delay in the presentation of breast symptoms for consultant investigation. Community Medicine 1981; 3: 217-25. 